\title{
NUMERICAL ANALYSES AND EXPERIMENTS OF DEFORMABLE RUBBER MEMBRANE PARAPETS
}

\author{
Insik Chun ${ }^{1}$, Sunsin Kim² ${ }^{2}$ Janghee $\mathrm{Ko}^{3}$ and Woosun Park $^{4}$
}

\begin{abstract}
It has been reported that global warming has invoked an ever increasing typhoon intensity as well as a long-term rise in sea levels which jointly cause severe coastal wave overtopping. A simple measure to cope with this undesirable change is to simply increase the crest height of coastal structures. This measure is certainly effective in the prevention of wave overtopping, but it can also reduce coastal visibility and lead to the degradation of waterfront seascapes. In this paper, Deformable Rubber Membrane Parapets (DRMP), which not only suppress the wave overtopping in storm periods, but also can retain coastal seascapes in milder conditions, are presented. With numerical analyses using a nonlinear finite element program and hydraulic experiments, the air controlled expansion and contraction of the parapets are investigated, together with their structural behaviors and stability against wave overtopping.
\end{abstract}

Keywords: rubber membrane parapet, LS-DYNA, deformable structure, wave overtopping

\section{INTRODUCTION}

Global warming is now being acknowledged as an undisputed fact, the effect of which we will have to mitigate or cope with in the future. From the viewpoint of coastal disasters, it has dual adverse effects, sea level rise and sea water temperature increases. The former may induce more frequent coastal inundations, and the latter often causes typhoons to be intensified to a greater degree by providing more energy in the form of vapor and heat.

According to Korea Hydrographic and Oceanographic Administration (2008), the global temperature has increased by $0.74^{\circ} \mathrm{C}$ in the past 100 years (1906 2005) and sea levels are rising by $1.8 \mathrm{~mm}$ every year (1961 2003). They showed even higher increases in temperature over 100 years and annual sea level rise in Korea, recording $1.5^{\circ} \mathrm{C}$ and $1.9 \mathrm{~mm}$ (1964 2006) respectively. In particular, Jeju Island has shown a very rapid sea level rise of about $5.1 \mathrm{~mm}$ every year, which has accumulated to $22 \mathrm{~cm}$ for the past 40 years. On the other hand, the National Emergency Management Agency (2005) reported that the top ranked 6-7 typhoons in terms of property damage had occurred in the past 10 years (before 2005). Moreover, the recent occurrence of unusually high waves on the east and west coasts are also being recognized as phenomena which are partly affected by the global warming effect.

The combined effect of the sea level rise and typhoon intensification surely results in the relative decrease of the crest heights of breakwaters or sea walls. This causes an increase in wave overtopping, which in turn leads to the degradation of harbor tranquility and damages to coastal facilities. As one of the methods to avoid these unwanted natural hazards, the simple enhancement of the crest height of structures may be the first option considered in many cases. Fig. 1 shows an example of a breakwater with a very large crest height. At first glance, this method looks like the most direct measure to prevent excessive wave overtopping, but at the same time it can lower seaward visibility, degrading the overall seascapes of water fronts. As a method to resolve this contradictory problem, deformable rubber membrane parapets can be effectively employed.
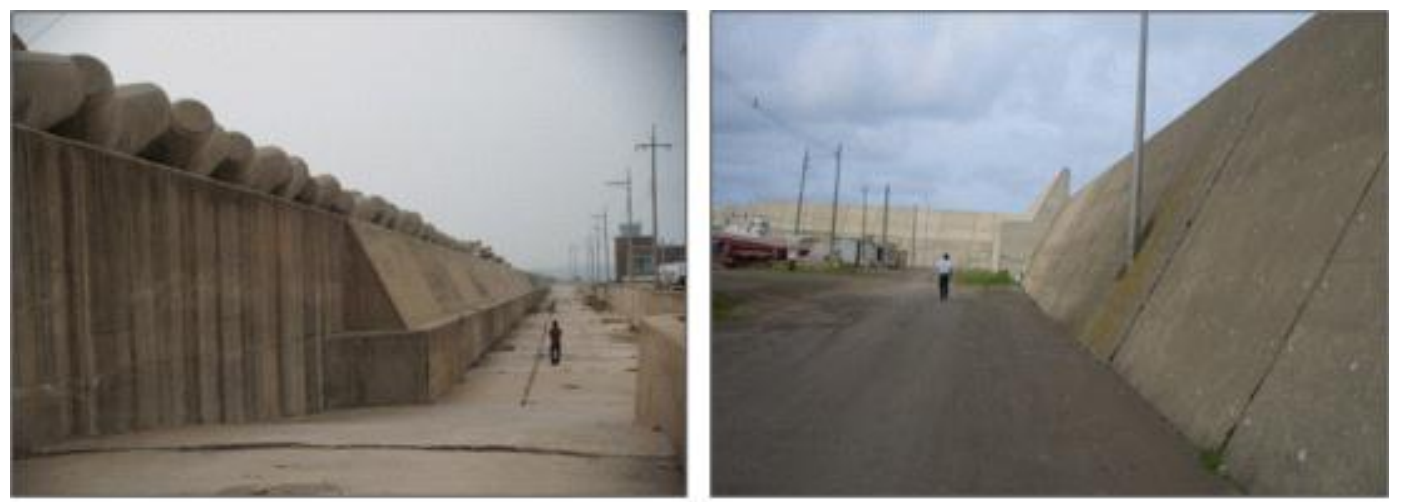

Figure 1. Breakwaters with very large crest height.

\footnotetext{
${ }^{1}$ Dept. of Civil Engineering, Konkuk University, 120 Neungdong-ro, Gwangjin-gu, Seoul, 143-701, Korea

${ }^{2}$ Dept. of Civil Engineering, Konkuk University, 120 Neungdong-ro, Gwangjin-gu, Seoul, 143-701, Korea

${ }^{3}$ SK E\&C, Myeong-dong B/D \#59-5, 78 Namdaemun-ro, Jung-gu, Seoul, 100-021, Korea

${ }^{4}$ Korea Institute of Ocean Science \& Technology, 787 Haean-ro, Sangnok-gu, Ansan, Gyeonggi, 426-744, Korea
} 
The rubber membrane parapet is configured as shown in Fig. 2. It is stowed in a flat storage in normal weather conditions, but can be expanded in stormy weather conditions, by air pressure control, to increase the overall crest height. The total time that previous designs of fixed structures are really in effect is not so long, and hence, the excessive crest height could be said to be an unnecessary sacrifice of coastal seaward view for the most of the time. The rubber membrane parapet, however, can ensure both coastal stability and security, as well as seaward visibility, simply by dynamically adjusting the crest height of the structure by remotely controlling the air supply depending on sea weather conditions.
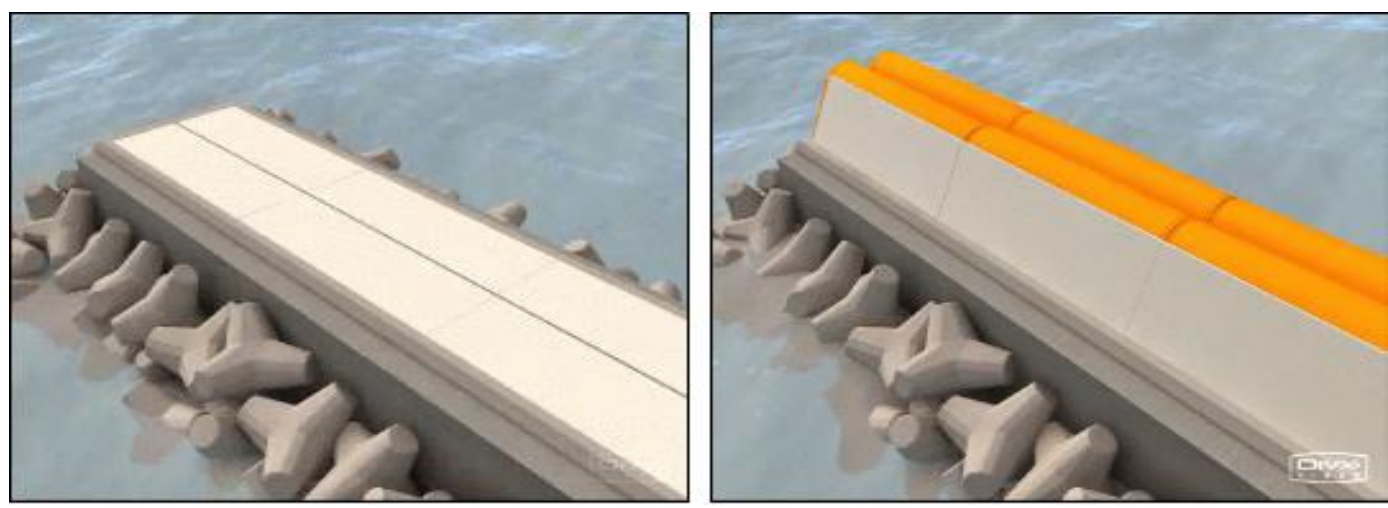

Figure 2. Rubber Membrane Parapet.

\section{CONFIGURATIONS OF RUBBER MEMBRANE PARAPET}

Considering various factors, including the ease of expansion and storage, overtopping suppressing capability, construction feasibility and outer appearance, five types of DRMP have been devised, and are represented in Fig. 3. The Frog, Pillow and Double Pillow types use a single protection cover. In the Twin and Sprout types, however, double covers are used with a middle sill which provides a support to any surcharges given by man or car traffic while in storage state. The Twin type has two symmetrical membranes to facilitate the additional energy dissipation by their mutual collision and friction for any overtopping occurrence. In the Pillow and Double Pillow types, strips are installed encompassing the expanded membranes to prevent rapid rotation of the covers when the membranes are quickly expanded.

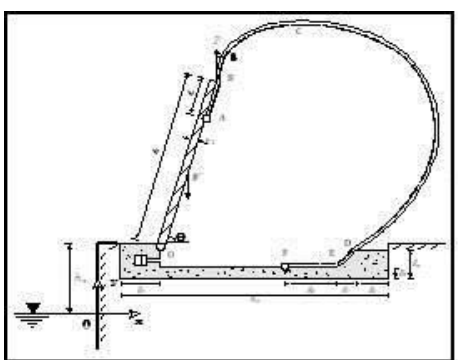

(a) Frogtype

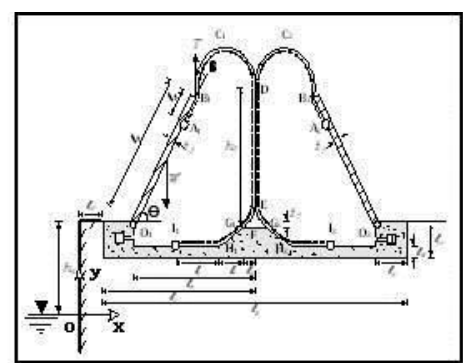

(b) Twintype

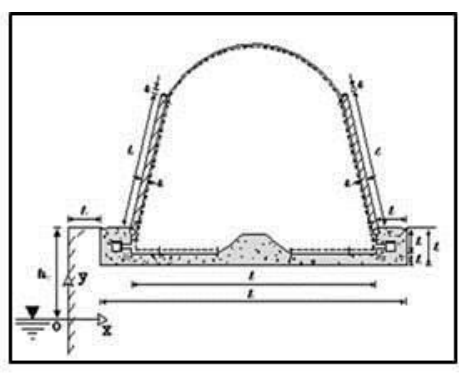

(c) Sprout type

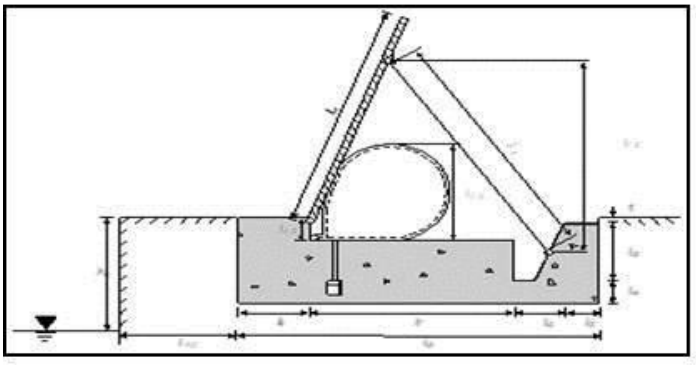

(d) Pillowtype

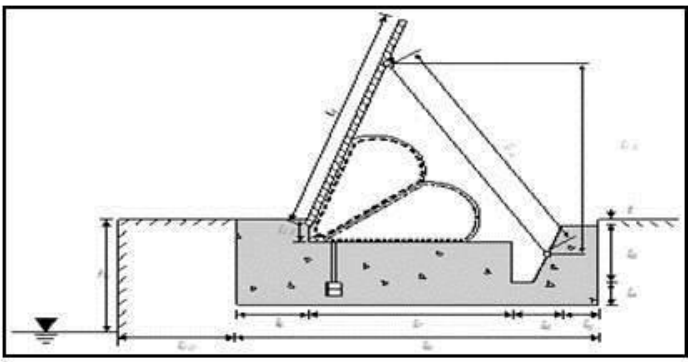

(e) Double Pillowtype

Figure 3. Proposed configurations of rubber membrane parapet. 


\section{NUMERICAL ANALYSES}

Numerical analyses were undertaken to investigate the feasibility of the rubber membrane parapets from different perspectives; air controlled operation of expansion and storage, and structural integrity against overtopping waves. The analyses were performed using a nonlinear FEM software package LSDYNA which can be efficiently employed in solving dynamic fluid-structure interactions. Of the five types above, only the Double Pillow type is demonstrated here.

The Double Pillow type is composed of a single cover, and two membranes and strips. Here, the material of the strips can be selected the same as that of the rubber membrane. The input conditions are as shown in Tables 1 and 2 . The inside pressure $315 \mathrm{kpa}$ was experimentally set so that the height of the cover above the hinge is lowered by wave action from its initial $2.0 \mathrm{~m}$ to $1.5 \mathrm{~m}$.

\begin{tabular}{|c|c|c|c|c|c|}
\hline $\begin{array}{l}\text { Structural } \\
\text { width }(m)\end{array}$ & $\begin{array}{c}\text { Cover } \\
\text { width }(m)\end{array}$ & Membrane length $(\mathrm{m})$ & $\begin{array}{c}\text { Storage } \\
\text { depth }(m)\end{array}$ & $\begin{array}{c}\text { Strip } \\
\text { length }(m)\end{array}$ & $\begin{array}{c}\text { Inside } \\
\text { pressure }(\mathrm{Pa})\end{array}$ \\
\hline 3.0 & 2.0 & $\begin{array}{l}\text { upper: } 2.85 \\
\text { lower: } 2.35\end{array}$ & 0.5 & 2.7 & 315,000 \\
\hline
\end{tabular}

Table 2. Properties of membrane

\begin{tabular}{|c|c|c|c|c|c|}
\hline $\begin{array}{c}\text { Fabric } \\
\text { material }\end{array}$ & Spec. tension & No. of layer & Fabric thickness & $\begin{array}{c}\text { Membrane thickness } \\
\text { (fabric + rubber coating) }\end{array}$ & $\begin{array}{c}\text { Allowable } \\
\text { tension }\end{array}$ \\
\hline \multirow{2}{*}{$\mathrm{ND}-220$} & $220 \mathrm{kgf} / \mathrm{cm}$ & 4 & $0.0048 \mathrm{~m}$ & $0.012 \mathrm{~m}$ & $776,160 \mathrm{~N} / \mathrm{m}$ \\
\cline { 3 - 6 } & & 5 & $0.0060 \mathrm{~m}$ & $0.015 \mathrm{~m}$ & $970,200 \mathrm{~N} / \mathrm{m}$ \\
\hline
\end{tabular}

The expansion and storage of the double pillow type was examined, and it was ensured that it was fully operational based on the control of the inside air pressure. The process is as shown by Fig. 4 .

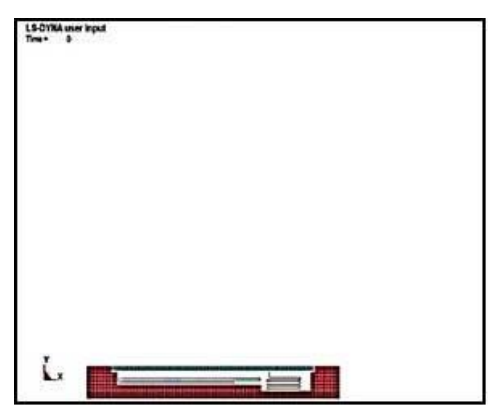

(a) Initial stage

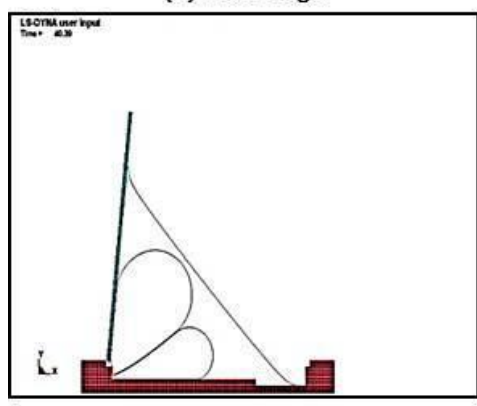

(d) Contraction-1

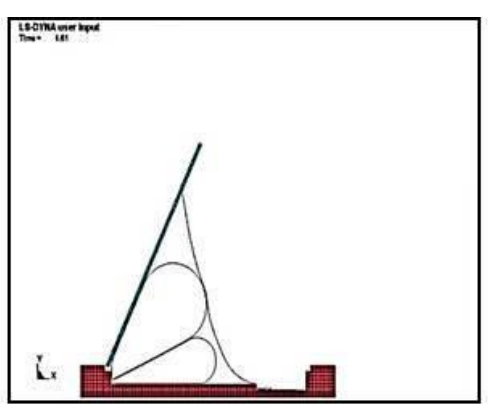

(b) Expansion

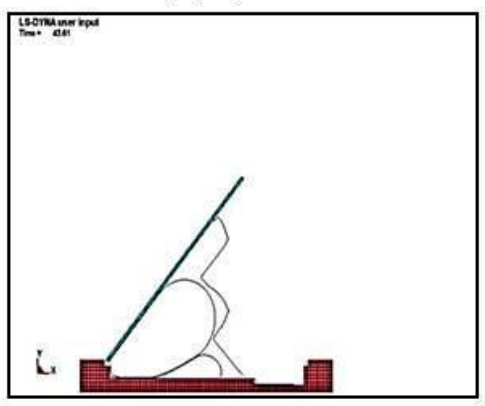

(e) Contradion-2

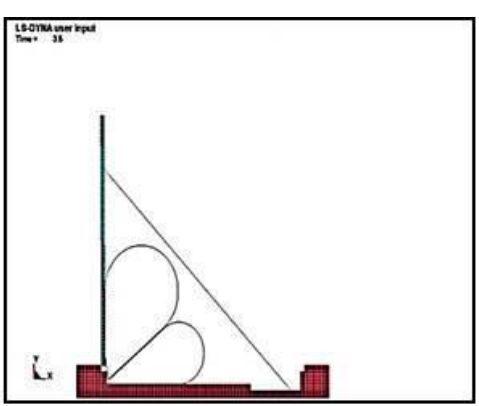

(c) Full expansion

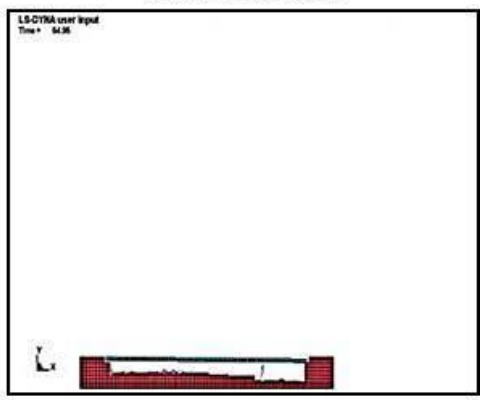

(f) Storage

Figure 4. Process of the expansion and contraction of the Double Pillow type. 
The structural analysis was done with the 3D simulation for a $10 \mathrm{~m}$ span. For the full expansion state of the parapet, we applied the calculations of Goda (1985) for breaking wave pressures on the cover which corresponded to wave height of $4.28 \mathrm{~m}$ and period of $12.7 \mathrm{~s}$ as shown in Fig. 5. The shapes of the parapet before and after the application of wave pressure are as presented in Fig. 6.

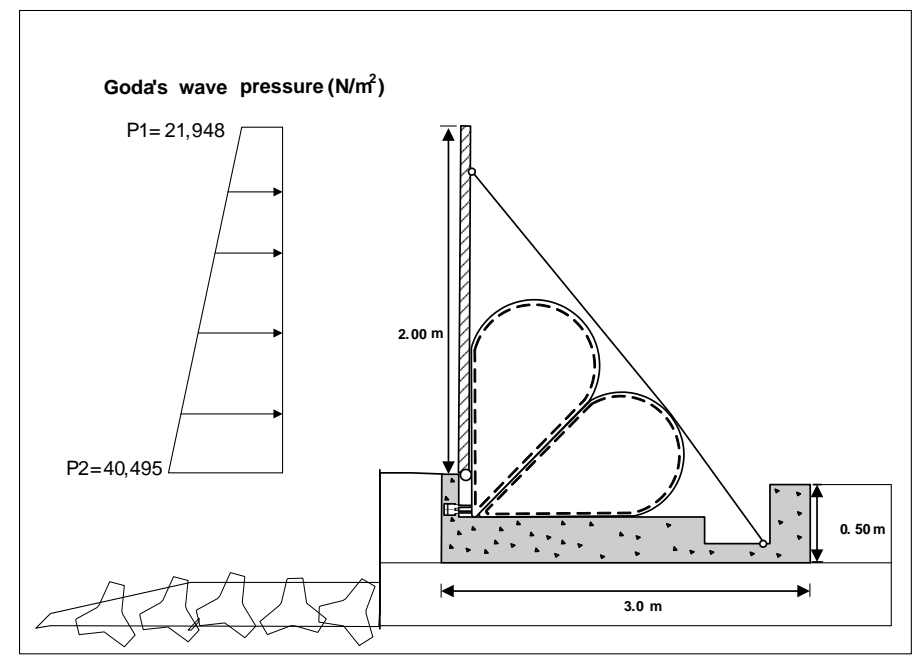

Figure 5. Application of wave pressure to the parapet.

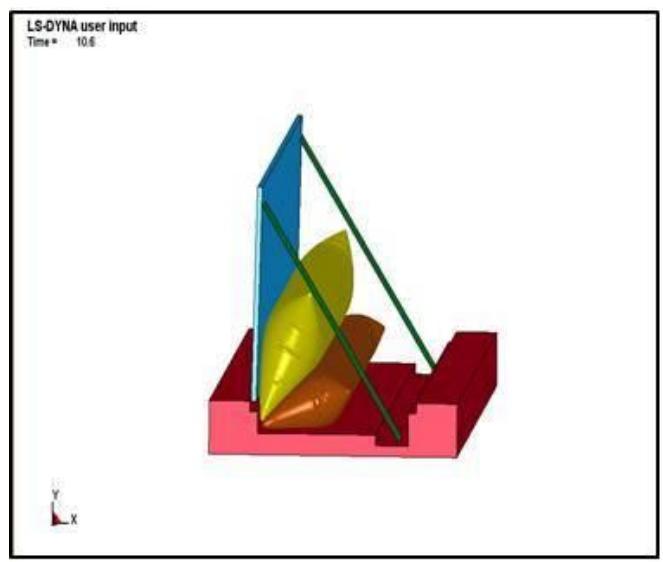

(a) Before waveattack

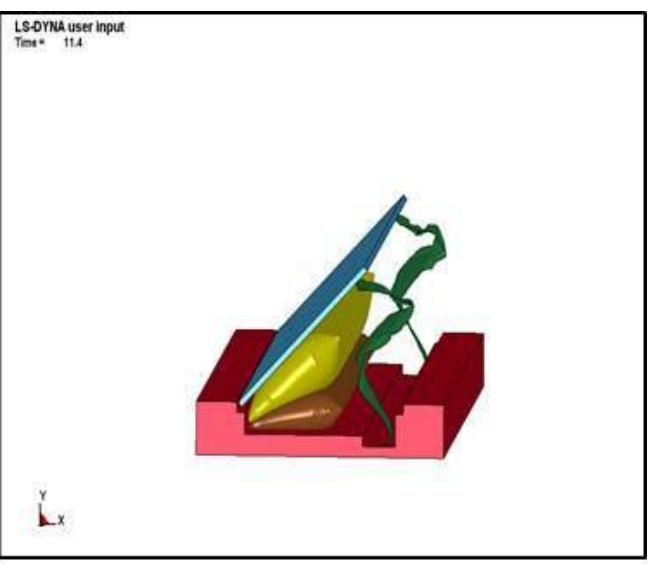

(b) After wave attack

Figure 6. Deformation of the parapet due to wave attack.

The structural analysis showed that the maximal tensions of both the upper and lower membranes were less than their allowable tensions, returning safety factors greater than 3.0. The results are presented in Table 3, Fig. 7 and Fig. 8.

\begin{tabular}{|c|c|c|c|c|}
\hline \multicolumn{5}{|l|}{ Table 3. Result of the structural analysis } \\
\hline Items & Max. principal stress $\left(\mathrm{N} / \mathrm{m}^{2}\right)$ & Max. tension $(\mathrm{N} / \mathrm{m})$ & Allowable tension $(\mathrm{N} / \mathrm{m})$ & Safety factor \\
\hline $\begin{array}{c}\text { Upper } \\
\text { membrane }\end{array}$ & $15,875,800$ & 190,510 & 776,160 & 4.07 \\
\hline $\begin{array}{c}\text { Lower } \\
\text { membrane }\end{array}$ & $20,481,100$ & 245,773 & 776,160 & 3.16 \\
\hline
\end{tabular}




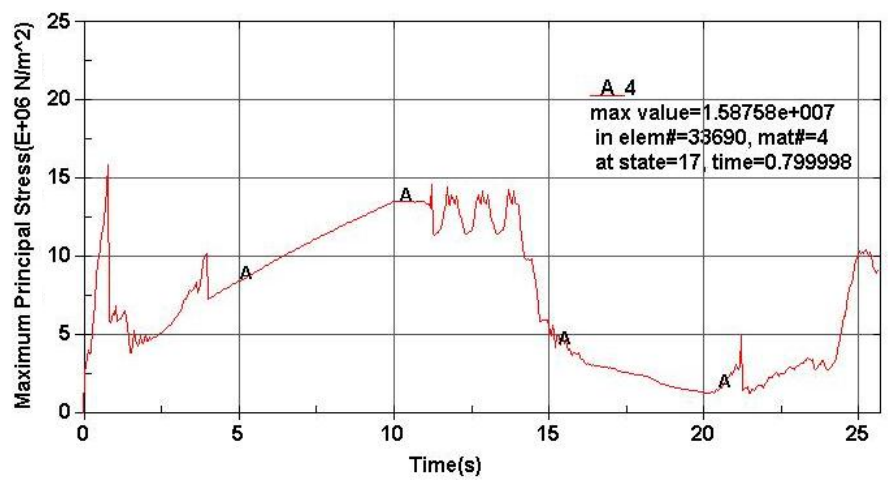

Figure 7. Time variation of the principal stress on the upper membrane.

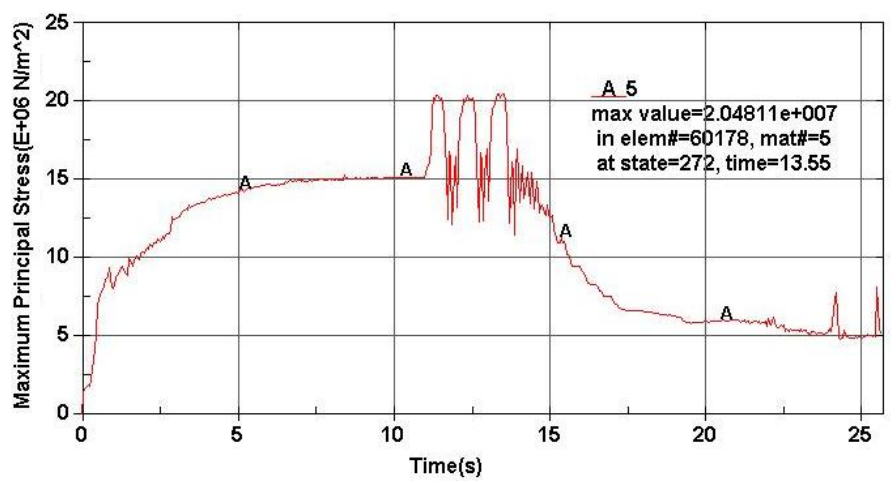

Figure 8. Time variation of the principal stress on the lower membrane.

\section{HYDRAULIC EXPERIMENTS}

Hydraulic experiments were carried out for the Double Pillow type to investigate the overall fabrication process, air controlled operation and hydraulic characteristics of wave reflection, transmission and wave overtopping.

The detailed configuration of the experimental mode of the parapet is as shown in Fig. 9.

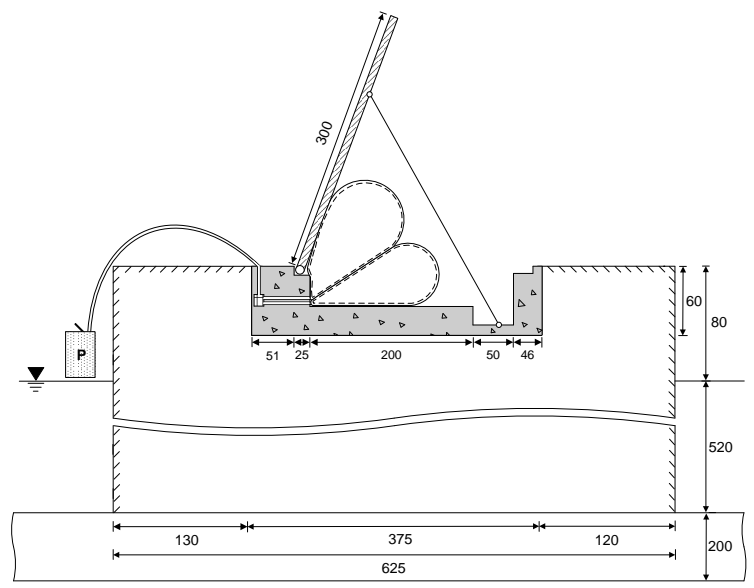

Figure 9. Experimental structure.

Prior to the experiment, the expansion and collapse of the parapet were checked with the air pressure inside varied. The measured height of the parapet was found to be almost identical to the calculated value as shown Fig. 10 and Table 4. 


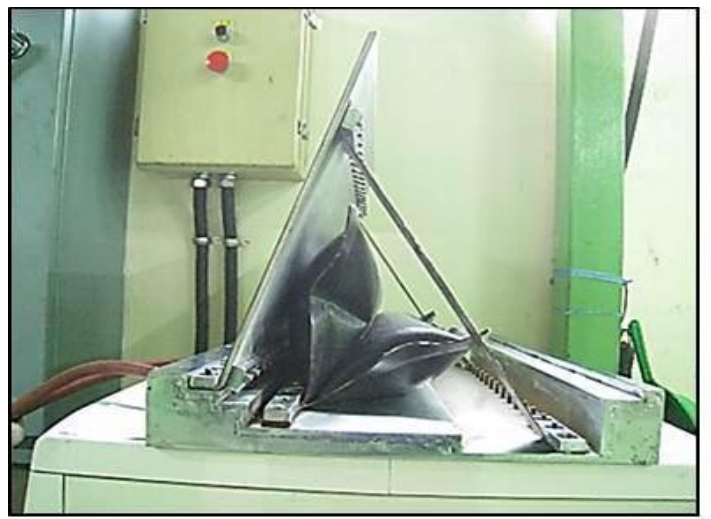

(a) Hydraulic experiment

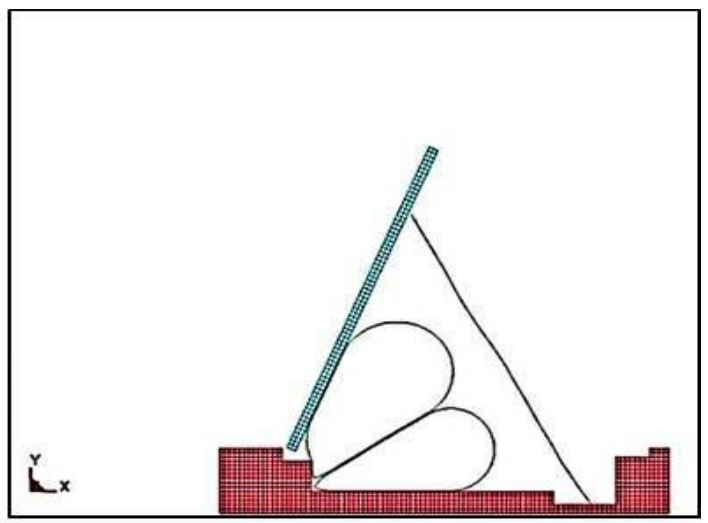

(b) Numerical analysis

Figure 10. Comparison of parapet height.

Table 4. Comparison of the crest heights between the hydraulic experiment and numerical analysis

\begin{tabular}{|c|c|c|}
\hline Items & Calculated & Measured \\
\hline Inside pressure(MPa) & 0.02 & 0.02 \\
\hline Parapet height(cm) & 27.6 & 28.2 \\
\hline
\end{tabular}

The experiments were carried out in the two dimensional wave flume of the Korea Ocean Research and Development Institute as represented in the schematic of Fig. 11. A false bed was installed to control the experimental waves.

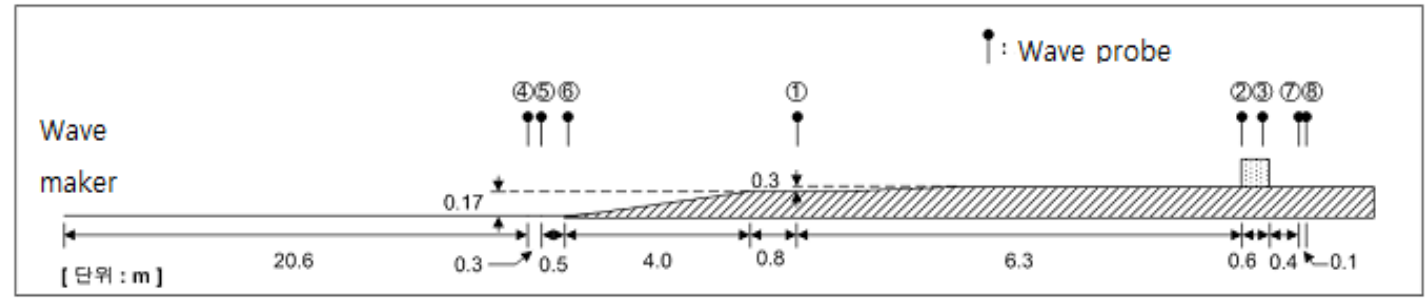

Figure 11. Experimental flume.

The air pressure inside was varied with three fixed values as shown in Table 5. The water depth was constantly maintained to be $0.52 \mathrm{~m}$ in all experiments.

\begin{tabular}{|c|c|c|c|c|c|}
\hline Wave & $\begin{array}{l}\text { Depth } \\
d(\mathrm{~m})\end{array}$ & $\begin{array}{l}\text { Wave period } \\
T(\mathrm{sec})\end{array}$ & $\begin{array}{c}\text { Wave height } \\
H(\mathrm{~cm})\end{array}$ & $\begin{array}{c}\text { Air pressure } \\
P(\mathrm{kPa})\end{array}$ & Remarks \\
\hline \multirow{3}{*}{$\begin{array}{l}\text { Regular } \\
\text { (RE) }\end{array}$} & \multirow{3}{*}{0.52} & \multirow{3}{*}{$\begin{array}{c}1.4 \sim 3.0 \\
(0.2 s \text { interval) }\end{array}$} & \multirow[t]{2}{*}{$15.0(\mathrm{H} 1)$} & $0.0(\mathrm{P} 0)$ & \multirow{3}{*}{$\begin{array}{l}\mathrm{P} 0: \text { closed } \\
\mathrm{P} 1: 15.0 \mathrm{~cm} \text { parapet height } \\
\mathrm{P} 2: 28.2 \mathrm{~cm} \text { parapet height } \\
\text { (full expansion) }\end{array}$} \\
\hline & & & & $4.0(\mathrm{P} 1)$ & \\
\hline & & & $17.0(\mathrm{H} 2)$ & 20.0(P2) & \\
\hline \multirow{3}{*}{$\begin{array}{l}\text { Irregular } \\
\quad \text { (IR) }\end{array}$} & \multirow{3}{*}{0.52} & \multirow{3}{*}{$\begin{array}{c}1.4 \sim 3.0 \\
(0.2 \mathrm{~s} \text { interval) }\end{array}$} & \multirow{3}{*}{$15.0(\mathrm{H} 1)$} & $0.0(\mathrm{P} 0)$ & \multirow{3}{*}{$\begin{array}{l}\text { P0 : closed } \\
\text { P1 }: 15.0 \mathrm{~cm} \text { parapet height } \\
\text { P2 }: 28.2 \mathrm{~cm} \text { parapet height } \\
\text { (full expansion) }\end{array}$} \\
\hline & & & & $4.0(P 1)$ & \\
\hline & & & & $20.0(\mathrm{P} 2)$ & \\
\hline
\end{tabular}


Fig. 12 shows the operation of the parapet during wave overtopping. The operation of expansion and collapse were well proceeded during wave collision.

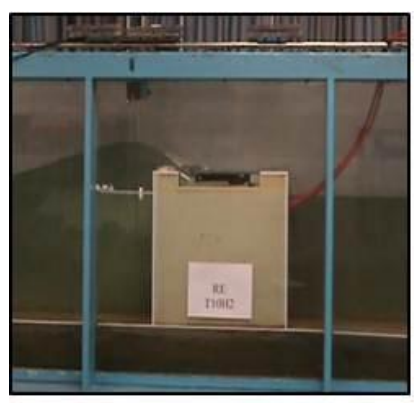

(a) Storage state

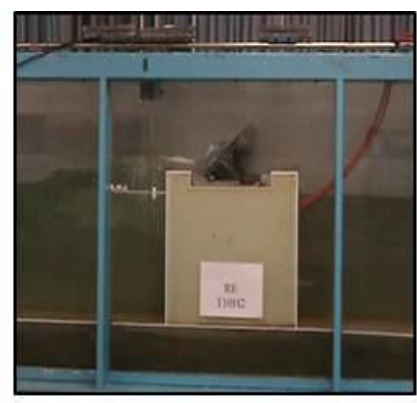

(b) Half expansion

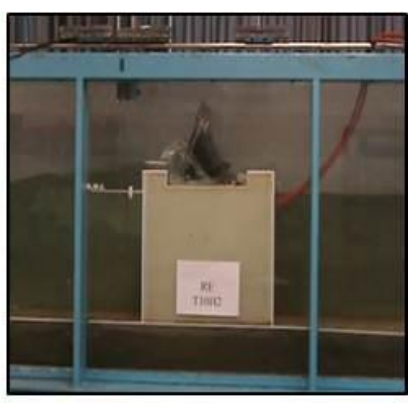

(c) Full expansion

Figure 12. Rubber parapet deforming with the internal pressure varied.

The change of non-dimensional wave overtopping $q / \sqrt{2 g\left(H_{0}\right)^{3}}$ with the change of $d / L$ was evaluated. Here, $L$ denotes wave length. Fig. 13 and Fig. 14 show the results for regular and irregular wave conditions. As physically expected, the irregular wave conditions show wave overtopping greater than the regular wave conditions show. In both wave conditions, wave overtopping is quite significant in the state of full collapse of the parapet (P0). But it can be observed that they drop down to almost negligible values in the state of half expansion (P1), even showing no wave overtopping in full expansion $(\mathrm{P} 2)$.

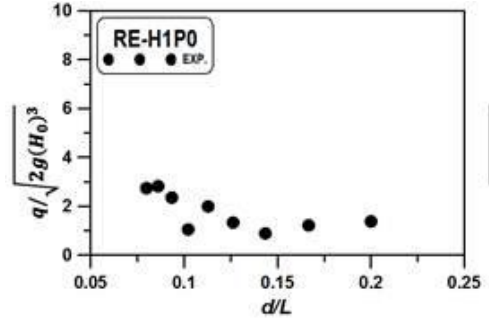

(a)

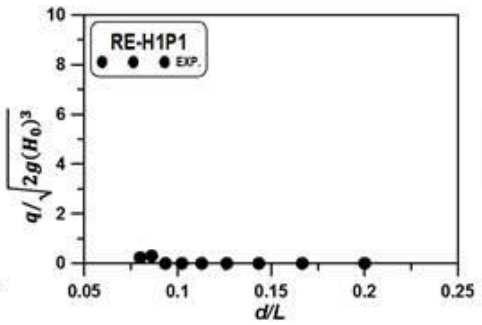

(b)

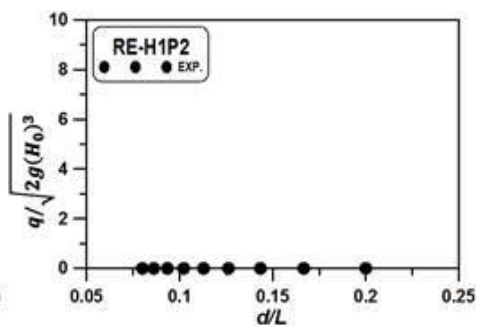

(c)

Figure 13. Overtopping rate (regular wave, wave height $15.0 \mathrm{~cm}$ ).

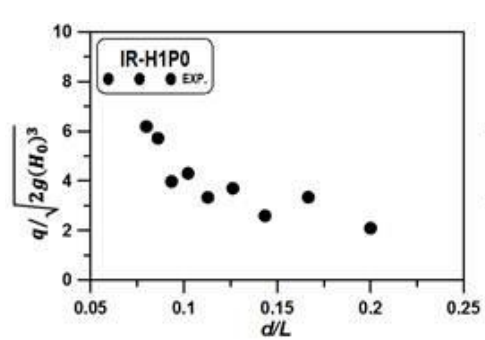

(a)

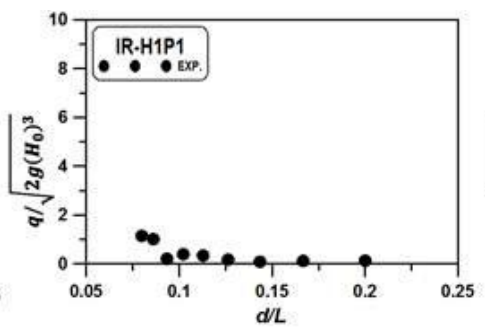

(b)

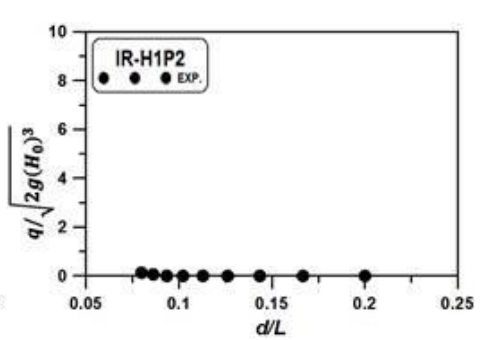

(c)

Figure 14. Overtopping rate (irregular wave, wave height $15.0 \mathrm{~cm}$ ).

\section{IN-SITU EXPERIMENT}

An in-situ experiment has been carried out in order to check the overall process of parapet fabrication and construction, structural stability and hydraulic performance for real sea waves. The breakwater of Deoksan port in the east coast of Korea was chosen since it had been reported to experience frequent wave overtopping. The experimental parapet was $2.9 \mathrm{~m}$ high at its full expansion, and was $3.5 \mathrm{~m}$ wide and $10 \mathrm{~m}$ long.

The wave conditions at the site were statistically and numerically investigated, and finally a wave condition with 10 -year return period was taken to give the input wave pressure needed for structural 
analysis. The structural units were separately manufactured in the factory and the air balloons were tested for air tightness. All units were then transported to the site and were assembled. Fig. 15 shows the assembling process at the site which took just over 1 day for completion. A 5 horsepower air compressor was used to supply air to the membrane balloons, through a pipe of $2 \mathrm{~cm}$ diameter. The air supply up to the full expansion took approximately 20 minutes. The operation of the air supply and drainage was performed in a well sheltered location remote to the structure.
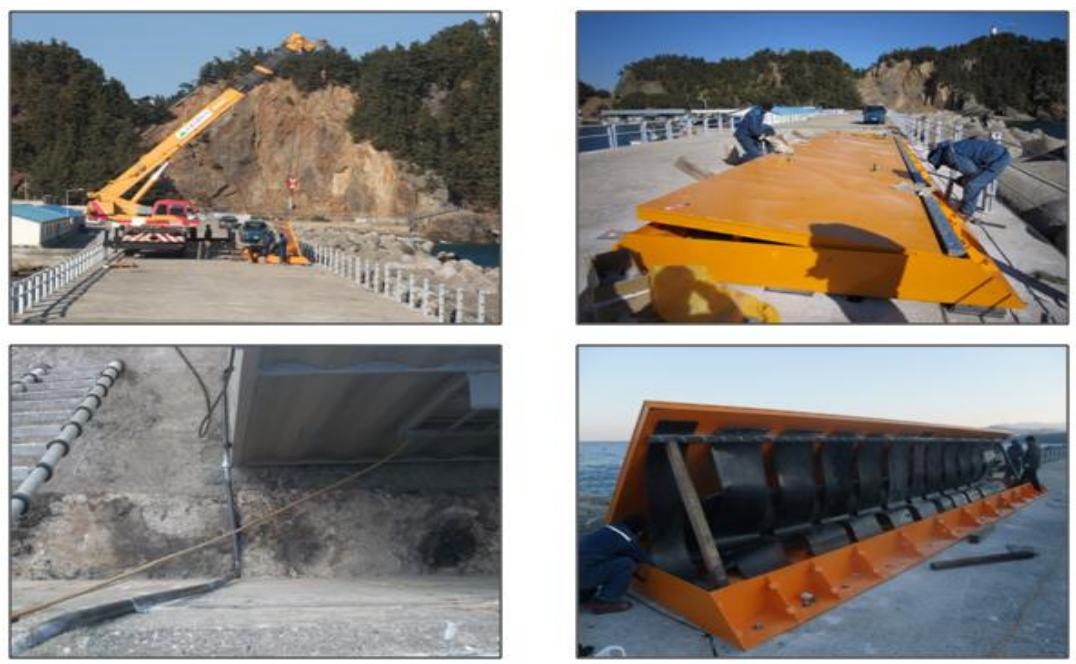

Figure 15. Assembling process of DRMP at the site.

The field observation begun in Feb. 2011 and is still on going to capture incidents of violent wave overtopping, such as that shown in Fig. 16. Notable waves are continuously monitored by a pressure type wave gauge which was installed about $300 \mathrm{~m}$ off the breakwater at a depth of $9.5 \mathrm{~m}$.

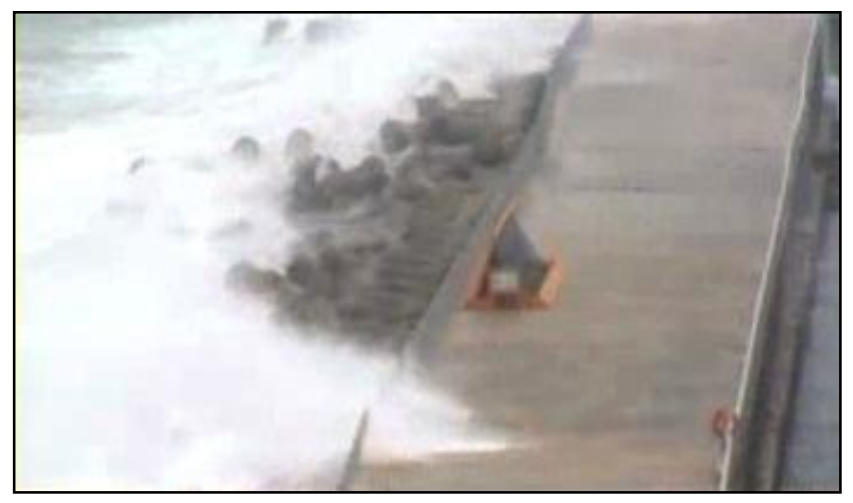

Figure 16. In-situ experiment.

\section{Acknowledgments}

This research was supported by the governmental project $(2006-2010)$ 'Establishment of the engineering foundation of harbor remodeling works'.

\section{REFERENCES}

Goda, Y. 1985. Random seas and design of maritime structures, University of Tokyo Press.

Korea Hydrographic and Oceanographic Administration. 2008. Annual sea level rise around korea (News release), http://www.khoa.go.kr/news/press_view.asp?borad_no=1154.

LS-DYNA. 2006. Theory Manual, LIVERMORE SOFTWARE TECHNOLOGY CORPORATION.

National Emergency Management Agency, 2005. Historic rank of damages due to heavy rain falls and typhoons, http://www.nama.go.kr/nema_cms_iba/show_nema/board/board9s/view.jsp. 